\title{
Prompt penetration electric fields (PPEFs) and their ionospheric effects during the great magnetic storm of 30-31 October 2003
}

\author{
B. T. Tsurutani, ${ }^{1,2}$ O. P. Verkhoglyadova, ${ }^{2,3}$ A. J. Mannucci, ${ }^{1}$ A. Saito, ${ }^{4}$ T. Araki, ${ }^{4}$ \\ K. Yumoto, ${ }^{5}$ T. Tsuda, ${ }^{2}$ M. A. Abdu, ${ }^{6}$ J. H. A. Sobral, ${ }^{6}$ W. D. Gonzalez, ${ }^{6}$ H. McCreadie, ${ }^{7}$ \\ G. S. Lakhina, ${ }^{8}$ and V. M. Vasyliūnas ${ }^{9}$
}

Received 15 October 2007; revised 21 January 2008; accepted 13 February 2008; published 17 May 2008.

[1] We explore the ionospheric effects of prompt penetration electric fields (PPEFs) for a variety of interplanetary magnetic field directions. We use the great magnetic storm of 30-31 October as an example of PPEF effects. For intense southward interplanetary magnetic fields (IMFs), inward plasma sheet convection occurs with the result of magnetospheric ring current formation and an intense magnetic storm. Concurrent with the above, positive phase ionospheric storms occur in the dayside, and negative phase ionospheric storms occur on the nightside, the topics of this paper. The dayside ionospheric storms due to PPEFs are characterized by transport of near-equatorial plasma to higher altitudes and latitudes, forming a giant plasma fountain. These features are part of what is called the dayside ionospheric superfountain (DIS). For these southward IMFs, dusk and dawn plasma are predicted to be transported toward the dayside. For northward IMFs, negative phase ionospheric storms are expected on the dayside if the PPEFs indeed reach that region of space. IMF By components are expected to have weak or neglible ionospheric effects. On the basis of PPEF arguments, intervals of IMF By should not be related to geomagnetic storms (they are not). IMF By intervals should, however, cause a shearing of the magnetotail, a feature that has been previously reported in the literature.

Citation: Tsurutani, B. T., et al. (2008), Prompt penetration electric fields (PPEFs) and their ionospheric effects during the great magnetic storm of 30-31 October 2003, J. Geophys. Res., 113, A05311, doi:10.1029/2007JA012879.

\section{Introduction}

[2] Although interplanetary-ionospheric coupling has been recognized as an important physical process since the 1960s [Obayashi, 1967; Nishida, 1968; Kelley et al., $1979,2003]$, the effect of this coupling was not fully appreciated until the last decade when there was a focus on what is now called "space weather." Scientists collectively studied a broad view of solar-interplanetary-magnetosphericionospheric (SIMI) coupling processes that are taking place in our heliosphere, from the Sun to our atmosphere during this world-wide effort. Additionally, the development and use of modern technology such as the global positioning system

\footnotetext{
${ }^{1}$ Jet Propulsion Laboratory, California Institute of Technology, Pasadena, USA.

${ }^{2}$ RISH, Kyoto University, Uji, Kyoto, Japan.

${ }^{3}$ IGPP, University of California, Riverside, California, USA.

${ }^{4}$ KUGI, Kyoto University, Kyoto, Japan.

${ }^{5}$ SERC, Kyushu University, Fukuoka, Japan.

${ }^{6} \mathrm{INPE}$, Sao Jose dos Campos, Sao Paulo, Brazil.

${ }^{7}$ Department of Earth and Environmental Sciences, Ludwig-Maximilians University, Munich, Germany.

${ }^{8}$ Indian Institute of Geomagnetism, Mumbai, India.

${ }^{9}$ Max Planck Institute for Solar System Research, Katlenburg-Lindau, Germany.

Copyright 2008 by the American Geophysical Union. 0148-0227/08/2007JA012879
}

(GPS) and ground and satellite GPS receivers for ionospheric research, have substantially sped up this discovery process.

[3] In this article we will focus on one major facet of space weather, that of prompt penetration electric fields (PPEFs) [Sastri, 1988; Abdu et al., 1995; Abdu, 1997; Sobral et al., 1997, 2001; S. Basu et al., 2001; Su.Basu et al., 2001; Sastri et al., 2002] and their ionospheric and magnetospheric effects. By the term "PPEF," we mean interplanetary motional electric fields that appear almost immediately in the Earth's ionosphere and magnetosphere after these electric fields have been convected by the solar wind to the magnetosphere. The electric fields are detected in the magnetosphere and at the Earth's ionospheric magnetic equator with intensities of $\sim 5$ to $10 \%$ of the interplanetary electric field intensities [Gonzalez et al., 1989, 1994; Kelley et al., 2003]. Several possible mechanisms which can explain such penetration have been presented in the literature [Dungey, 1961; Nopper and Carovillano, 1978; Kikuchi and Araki, 1979].

[4] We will discuss what effects PPEFs have on the magnetosphere and ionosphere. Different directions of the interplanetary magnetic field (IMF) will create different magnetospheric and ionospheric PPEFs, with substantially different outcomes. Thus, southward, northward and eastward/ westward IMF directions will be considered. It is hoped that the most useful part of this exercise will be to formulate 
predictions that have not been examined or tested to date. We hope this will be stimulating to scientists entering this field of research.

[5] It should be noted that what is actually observed in the solar wind as well as in the magnetosphere and ionosphere is not the electric field $\mathrm{E}$, but the plasma bulk flow velocity $\mathrm{V}$. The electric field is in most cases inferred by the use of the MHD approximation $\mathrm{E}=-\mathrm{V} \times \mathrm{B}$. The description in terms of $\mathrm{E}$ rather than $\mathrm{V}$ is, however, traditional and possesses some mathematical and conceptual advantages. For this reason, we refer to the electric field in this paper. It has been argued by Vasyliūnas [2001, 2005a, 2005b] that in strictly physical terms, $\mathrm{E}$ is merely a consequence of $\mathrm{V}$, the latter being determined by the stress acting on the plasma.

\section{Measurement and Modeling Techniques}

[6] Figure 1 shows a schematic of Global Positioning System (GPS) satellite signal reception used for ionospheric studies. There are 28 GPS satellites in circular orbit around the Earth. They are at an altitude of $\sim 20,200 \mathrm{~km}$ (only one satellite is shown for brevity). The satellites transmit omnidirectional signals at the dual frequencies of $\sim 1.2$ and $\sim 1.5 \mathrm{GHz}$. Ground and low-altitude satellite receivers detecting these signals are also shown in the figure. The differential phase delay between the two frequencies are directly related to the integrated column density of electrons along the signal path. Thus the total electron content (TEC) along the signal path is determined from the analyses of these two signals. In our application, an ionospheric model consisting of a fixed vertical profile of density is assumed to help interpret the multiple observations obtained at varying slant angles. For example, for satellites within the ionosphere, a spherical shell of $700 \mathrm{~km}$ thickness is used to normalize "slant path" values to "vertical" TEC values so that data obtained at varying slant angles can be intercompared without concern for geometrical path lengths through the ionosphere (for a general discussion of the method of GPS signal reduction, see Mannucci et al. [1998]). In this paper, only measurements within $50^{\circ}$ of zenith are used in order to minimize errors in the vertical TEC determination.

[7] Ground-based receivers detect GPS signals that have penetrated the entire ionosphere. Thus after scaling to vertical values, they provide a measure of the vertical TEC of the entire ionospheric column near the station location. Since GPS receivers track several GPS satellites simultaneously, multiple independent determinations of the vertical TEC can be made at varying locations near the receiver. If these different determinations have similar values, then it can be assumed that the large scale uniformity of the ionosphere implicitly assumed in the verticalization calculations is valid. On the other hand if the different TEC determinations are different for the same ground station, this may imply that the ionospheric electron density gradients over that location are large. The latter has been observed to occur in the auroral zone ionosphere during a High-Intensity, Long-Duration, Continuous AE (HILDCAA) event [Tsurutani et al., 2006].

[8] GPS measurements from low-altitude satellites such as CHAMP and SAC-C will yield TEC measurements for only part of the ionosphere, the portion above the satellites. However, satellite GPS detectors have several advantages over stationary ground detectors. High-inclination low-altitude Earth orbiting satellites sweep rapidly over a range of latitudes and can cover areas such as oceans, etc. that are not well-covered by ground detectors. Additionally, if the ionosphere is convected upward (or downward) with time, satellite measurements provide direct information on these changes. We therefore view the two types of measurements, satellite and ground GPS receiver data, as complementary to each other. Both are needed to understand ongoing ionospheric dynamics.

\subsection{Calculation of the Ionospheric Electric Field}

[9] The dayside ionospheric electric field was calculated at the same local time as the CHAMP crossing for 30 October 2003. This has been done using the CHAMP scalar magnetometer data [see McCreadie and Iyemori, 2006]. As the CHAMP satellite crossed the magnetic dip equator, it sensed the effects of the equatorial electrojet (EEJ) current. The magnetic field associated with the EEJ was measured during the electric field event and was compared to a quiet time equatorial crossing. The magnetic field difference was found to be $\sim 90 \mathrm{nT}$. This was ascribed to an enhanced eastward electric field present within the EEJ region during the 30 October event. We calculate a Cowling conductivity [Hirono, 1950] of $1.9 \times 10^{-2} \mathrm{sm}^{-1}$. This calculation was based on Hall and Pederson conductivities from the Kyoto University ionospheric model at local noon at $\sim 105 \mathrm{~km}$ altitude. Assuming a ground reflectance of $\sim 11 \%$ (A. Richmond, personal communication, 2006), and an infinite line EEJ current, an electric field enhancement of $\sim 4 \mathrm{mVm}^{-1}$ is derived. For the interested reader, more details can be found in Tsurutani et al. [2007] and Verkhoglyadova et al. [2006].

[10] This technique of obtaining an indirect measure of the dayside equatorial electric field is a variation of a twomagnetometer technique first suggested by Rostogi and Klobuchar [1990], and then later experimentally verified by Anderson et al. [2002, 2004]. This basic idea was utilized here with the CHAMP magnetometer using the above stated assumptions in order to obtain a quantitative estimate of the magnitude of the eastward PPEF.

\subsection{Ionospheric Model}

[11] The above ionospheric electric field was used as an input to a modified version of the NRL SAMI2 ionospheric model [Huba et al., 2000, 2002]. Descriptions of this modification (called SAMI2*) can be found in Verkhoglyadova et al. [2006]. SAMI2 is a low-latitude ionospheric model which describes dynamics and chemical evolution of seven ion species and correspondingly, seven neutral species. Collisions between electrons, ions and neutrals are taken into account. SAMI2 solves collisional MHD equations for electrons and ions along the Earth's dipole magnetic field lines, taking into account photoionization of neutrals, recombination of ions and electrons and chemical reactions. Drift of magnetic flux tubes defines the ionospheric plasma transport in a perpendicular direction to the magnetic field lines. The E x B vertical drift is caused by the eastward polarization electric field superimposed on the Earth background magnetic field. The SAMI2 diurnal variation electric field "sine" model is assumed for the results presented here. For this electric field, the drift velocity $\mathrm{Vd}$ is proportional to $\sin [(\mathrm{t}-7) / 24]$, where $\mathrm{t}$ is the 


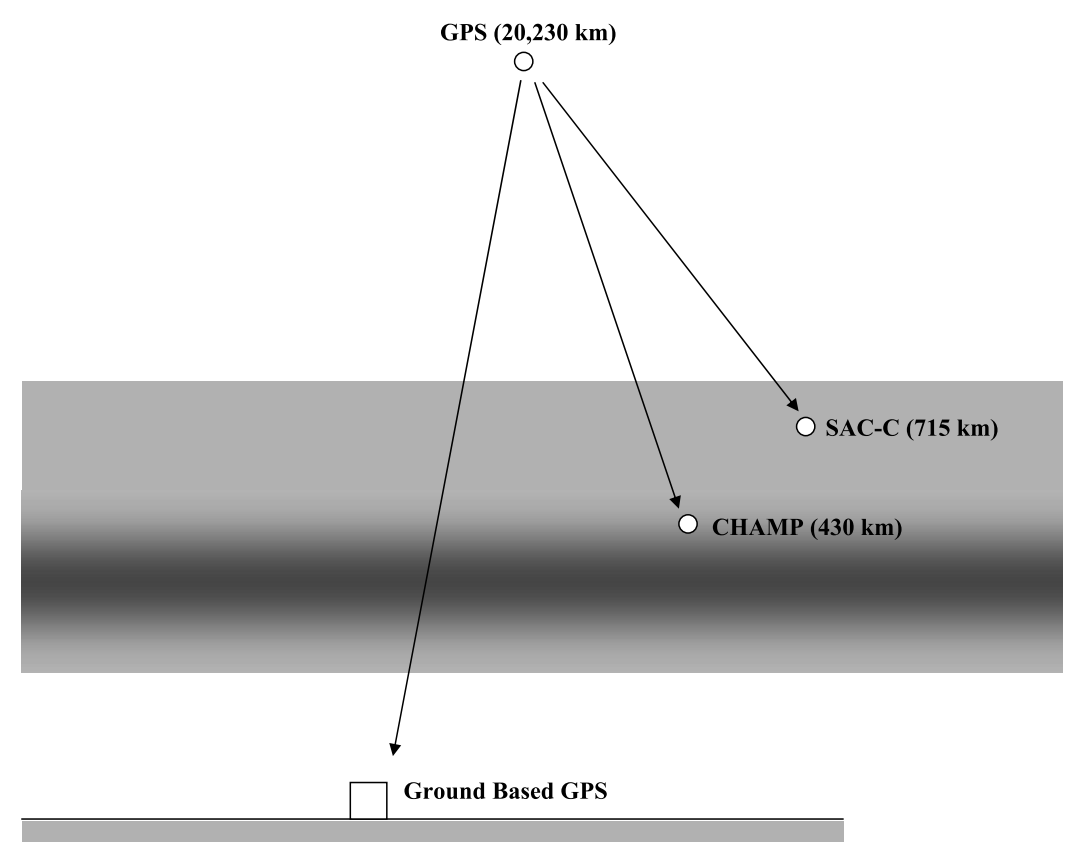

Figure 1. A schematic showing transmission of the dual GPS signals to ground-based GPS receivers and low-altitude polar-orbiting satellite GPS receivers. This figure is a modification of Figure 1 from Tsurutani et al. [2004]. Reduction of these signals are used to determine the total electron content of various aspects of the ionosphere.

local time in hours. The assumed Vd peak values are taken as $15 \mathrm{~m} / \mathrm{sec}$, which corresponds to a polarization electric field of $0.53 \mathrm{mV} / \mathrm{m}$.

[12] A second electric field is added to introduce a superposition of the PPEF to the "sine" field. We assume that the magnitudes of the electric fields in the ionospheric E- and $F$ regions are the same. This enhanced ionospheric electric field is applied at $12 \mathrm{LT}$ and terminated at $14 \mathrm{LT}$. This is done so that the effects of the PPEF could be determined during their first $\sim 2 \mathrm{~h}$ of existence in the ionosphere. For further details on SAMI2* and its application, we refer the reader to Verkhoglyadova et al. [2006].

[13] After $\sim 14$ LT, it is possible that storm-time disturbance dynamo effects [Blanc and Richmond, 1980; Prölss, 1997; Fuller-Rowell et al., 1998] could also be present. The dynamo is driven by energetic storm-time particle precipitation occurring primarily on the nightside auroral to middle latitude regions. The heating leads to a pressure wave that propagates to other longitudes and latitudes. Neutral-ion drag convects the ions away from the heating region. Upward motion of the plasma can be described in terms of convection electric fields. It is thought that the disturbance dynamo builds up at least $\sim 2$ to $4 \mathrm{~h}$ after interplanetary electric field (IEF) onset. Different computer models predict different time delays, so the latter is somewhat uncertain and variable. The discussion presented here in this paper is for the time interval prior to the potential arrival of disturbance dynamo effects.

\section{Fountain and Superfountain Effects: Basic Description}

[14] At dawn and thoughout the daytime hours, sunlight illuminates the atmosphere, both heating and photoionizing atoms and molecules. Thermal expansion of the atmosphere leads to upward motion of the neutrals, and strong neutralion collisions drag the ions along with the neutrals. The upward motion of ionospheric ions and electrons at the dip equator can also be thought of as the presence of an eastward electric field associated with $\mathrm{E} \times \mathrm{B}$ drift of the plasma. This eastward electric field produces the eastward EEJ with the aid of the enhanced Cowling conductivity at the dip equator.

[15] The ionospheric plasma is lifted up by the vertical $\mathrm{E} \times \mathrm{B}$ drift at the dip equator and goes down along geomagnetic lines of force to both sides of the equator. Plasma located slightly away from the equator is not only lifted upward but also displaced to higher latitudes. A dynamic equilibrium between $\mathrm{E} \times \mathrm{B}$ forces, gravitational forces and photoionization and recombination lead to ionospheric density enhancements located at $\sim \pm 10^{\circ}$ from the equator during geomagnetically quiet times. These latter maxima are called the Equatorial Ionospheric Anomalies or EIAs [Namba and Maeda, 1939]. This overall process of plasma uplift and the formation of the EIAs away from the equator is called the "fountain effect" since the plasma flow is like a fountain.

[16] During geomagnetic storms electric fields of solar wind origin penetrate into the magnetosphere and the dayside equatorial ionosphere. The penetration of these electric fields is very fast and they have been called "prompt penetrating electric fields or PPEFs for this reason. During very large storms (great magnetic storms), these electric fields are substantially larger than the fields associated with the normal fountain effect. If the interplanetary magnetic field is southward, leading to a dawn-todusk or dayside eastward electric field, this superposed electric field will enhance the normal fountain effect 


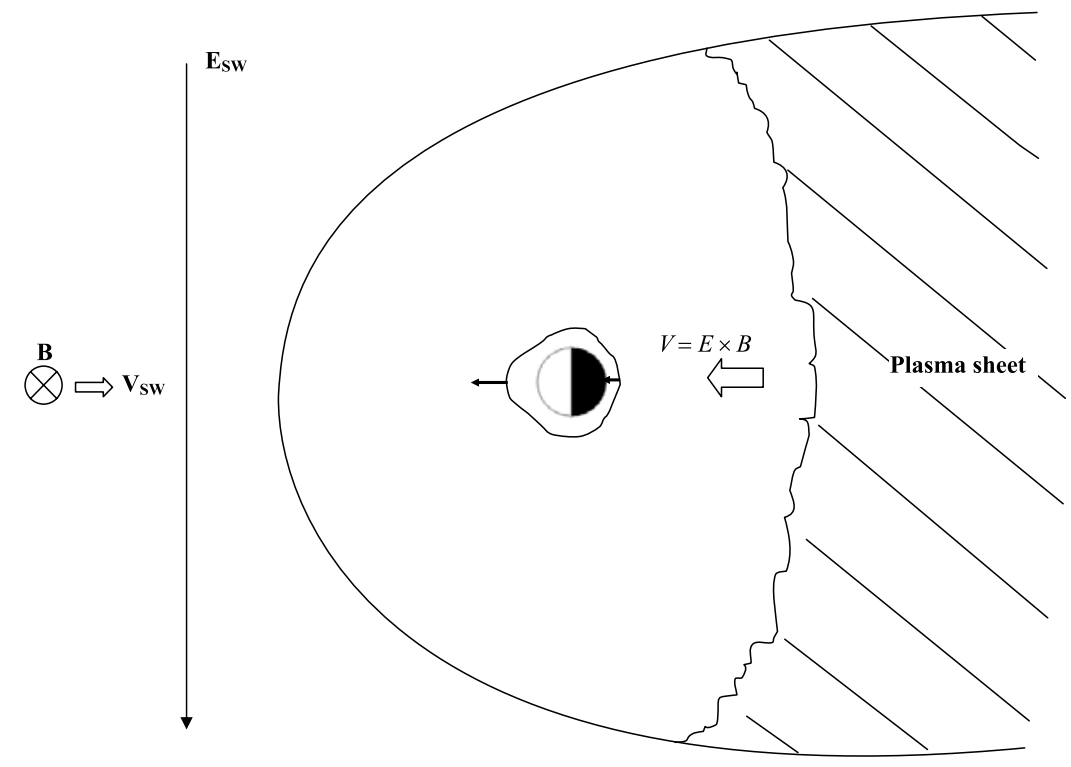

Figure 2. A schematic showing the interplanetary motional electric field (due to the solar wind convection of interplanetary magnetic fields past the Earth), and the prompt penetration of electric fields into the plasma sheet, the nightside equatorial ionosphere and the dayside equatorial ionosphere. This is Figure 11 from Tsurutani et al. [2004].

greatly. This has been called the superfountain effect. With the much larger electric fields, the dayside equatorial plasma will be lifted up to much higher altitudes and latitudes than normal. One consequence of the ionospheric plasma uplift is that the plasma will be transported to regions where recombination is much slower. Solar photoionization will restore plasma densities at lower altitudes, leading to substantial increases in the TEC of the heightintegrated ionospheric electrons (and ions). Since the dayside EIAs are not located at the equator, the $\mathrm{E} \times \mathrm{B}$ convection will transport EIA plasma not only to higher altitudes but also to higher (poleward) latitudes. The combination of solar photoionization and plasma transport will enhance EIA plasma densities to values above quiet time levels, creating a positive ionospheric storm. Specific observational and modeling results will be shown in this paper to illustrate these points. This overall dayside ionospheric effects associated with external interplanetary electric fields has been called the "dayside ionospheric superfountain (DIS) effect."

\section{Results}

\subsection{Prompt Penetration Electric Fields}

[17] Figure 2 is a schematic that shows the interplanetary magnetic field (IMF), interplanetary electric field (IEF), the resultant magnetospheric electric field and the effects of electric fields in the dayside and nightside equatorial ionosphere. Southward IMFs that are swept past the Earth's magnetosphere by the solar wind (at speeds ranging from $350 \mathrm{~km} / \mathrm{s}$ to over $1,000 \mathrm{~km} / \mathrm{s}$ ) are detected by the Earth as a motional electric field in the $-\mathrm{V} \times \mathrm{B}$ direction, i.e., from a dawn-to-dusk direction. If the transport of magnetic flux described by this electric field extends into the magnetosphere by magnetic reconnection [Dungey, 1961; Gonzalez and Mozer, 1974] or by some other process, then there must exist an $\mathrm{E} \times \mathrm{B}$ convection of the plasma sheet toward the Earth. The plasma will become compressed (heated) by the conservation of the first two adiabatic invariants and will eventually form the hot plasma of the storm-time energetic particle radiation belt. Due to magnetic field gradients and curvature, the ions will drift from the midnight sector toward dusk and the electrons toward dawn, forming a ring of current [Gonzalez and Tsurutani, 1987; Gonzalez et al., 1994]. This ring current is a diamagnetic one and causes a decrease in the Earth's magnetic field, as detected by nearequatorial ground-based magnetometers. Measurements of horizontal component decreases from several approximately equidistantly spaced magnetometers form the basis of the Dst or SYM-H magnetic storm indices.

[18] If the electric field penetrates into the dayside equatorial ionosphere, the plasma is convected toward higher altitudes (toward the Sun in the figure). At these higher altitudes, the recombination rates are considerably longer (hours) than for lower altitudes. Solar photoionization at lower altitudes continues to occur and will replace the uplifted ionosphere/plasma resulting in an overall TEC increase. This has been called a "positive phase" ionospheric storm. See the seminal paper by Prölss [1993] and also $\mathrm{Lu}$ et al. [2001] for general discussions of positive and negative phase ionospheric storms.

\subsection{Daytime Ionospheric Superfountain (DIS) Effect: Positive Phase Ionospheric Storms}

[19] Figure 3 illustrates the advantages of using multiple ground GPS receiver data. Data from $\sim 100$ receivers covering both local day and night are shown. Each ground station tracks multiple GPS satellites and the verticalized TEC data from each is shown. Various satellite TEC data are indicated in the figure.

[20] The top panel of the figure shows the global ionospheric TEC data during a quiet day. The event is from 
a.


Figure 3. Global maps of verticalized ground based GPS receiver data for a quiet day 27 October 2003 (top) and for the intense IEF/great magnetic storm of 30 October 2003 (bottom). During the intense IEF event, the dayside ionospheric TEC enhancement expands to $+40^{\circ}$ and $-20^{\circ}$. This latitudinal expansion is one feature of the dayside superfountain (DIS) effect.

2137 to 2223 UT on 27 October 2003. This was exactly three days prior to the interplanetary electric field event of interest. The data are plotted as a function of magnetic latitude (ordinate) and local time (abscissa). The north pole is at the top, equator in the middle and the south pole at the bottom. The subsolar point (equatorial noon) is at the center of the panel. The sunlit portion of the ionosphere is identified by the enhanced TEC region (red, yellow and green colors) near the center of the figure. There are only a few points in red at $\sim 1400$ LT near the equator, corresponding to $\sim 100$ TECU. The area of large dayside TEC values are noted in yellow and green from 10 to $18 \mathrm{LT}$ within $\pm 30^{\circ}$ latitude of the equator. The lowest TEC values are on the nightside and over the poles, as expected.

[21] The bottom panel of Figure 3 shows the global ionospheric TEC map after an intense IEF reached the magnetosphere on 30 October 2003. The UT, format and intensity scale are the same as those for the quiet day panel so that a direct intercomparison can be made. The dayside ionospheric TEC is now greatly enhanced and expanded in magnetic latitude. The dark-red and red region $(\sim 150-$ 120 TECU, where a TECU is $10^{16}$ electrons $/ \mathrm{m}^{2}$ ) extends from $+50^{\circ}$ MLAT to $-25^{\circ}$ MLAT (unfortunately the southernmost extent of the TEC enhancement is not well covered because of a lack of GPS ground receivers over the ocean). This effect is part of a dayside hemispherical positive phase ionospheric storm.

[22] There are also some spotty red areas at latitudes well above $50^{\circ}$ MLAT at 15 to 17 LT. These density enhancements are part of the "polar plume," often associated with superstorm events. The exact physical mechanism for these plumes and its relationship to PPEFs are not understood at this time. However, for the interested reader, we refer them to Mannucci et al. [2005a], Foster et al. [2005], and Foster and Coster [2007].

[23] The interplanetary southward magnetic field also caused a major magnetic storm. However, for brevity, this magnetospheric response will not be discussed further in this paper. There is a special issue of Geophysical Research Letters [2005], covering various aspects of the "Halloween 2003 superstorms" for interested readers.

[24] Figure 4 shows a different perspective of a positive phase dayside ionospheric storm and another feature of the DIS effect [Mannucci et al., 2005b]. The figure shows the TEC data at altitudes above the CHAMP satellite during the same interplanetary electric field event as that on 30 October 2003. This event was one of the famous "Halloween" magnetic storms. CHAMP was at an altitude of $\sim 430 \mathrm{~km}$ and crossed the dayside equator at $\sim 1300 \mathrm{LT}$. Three consecutive dayside passes are shown. The first pass at $\sim 1840$ UT occurred prior to the IEF impingement onto the magnetosphere. The latter two CHAMP tracks (2012 UT and 2143 UT) occurred after the IEFs reached the magnetosphere.

[25] In the first pass, the two EIAs are located at $\sim+10^{\circ}$ and $-10^{\circ}$ latitude. In the second pass (labeled 2012 UT), the anomaly peaks were detected at $\sim+22^{\circ}$ and $\sim-21^{\circ}$. The peak values of the latter had magnitudes of $\sim 200 \mathrm{TECU}$ above the CHAMP satellite. In the third CHAMP pass, the EIAs were located at $\sim+30^{\circ}$ and $\sim-30^{\circ}$ MLAT. The northern hemispherical peak had a $\sim 270$ TECU value $\sim 2 \mathrm{~h}$ 15 min after the impingement of the IEF onto the magnetosphere. The southern peak detected later in time was even higher with a value of $\sim 330$ TECU. This storm-time TEC value was well above quiet time levels.

[26] CHAMP had a TEC value of $\sim 200$ TECU at $-40^{\circ}$ latitude during the third pass. Thus the area that was not covered by the ground GPS receivers was covered by CHAMP. The TEC enhancement thus extended to at least $-40^{\circ}$ latitude in the southern hemisphere, making the ionospheric positive phase disturbance roughly symmetric.

\subsection{SAMI2* Dayside Ionospheric Modeling Results}

[27] Figure 5 shows the TEC predicted by SAMI2* at altitudes above $400 \mathrm{~km}$ at $25^{\circ}$ latitude. The TEC using the normal diurnal electric field (peak values of $0.53 \mathrm{mVm}^{-1}$ at 07 LT) is given by the curve indicated by stars. The TEC assuming a $4 \mathrm{mVm}^{-1}$ PPEF in addition to the sinusoidal diurnal electric field is indicated by triangles. In the storm electric field case, the TEC increases until $\sim 1515$ LT when a peak value of $\sim 270$ TECU is reached. This closely matches the peak EIA observed by CHAMP during the third CHAMP pass shown in Figure 4. A very good match between the SAMI2* simulations and the CHAMP measurements is found. This suggests that the very large electric field values derived using the CHAMP magnetometer measurements are quite plausible. This derived PPEF is a 


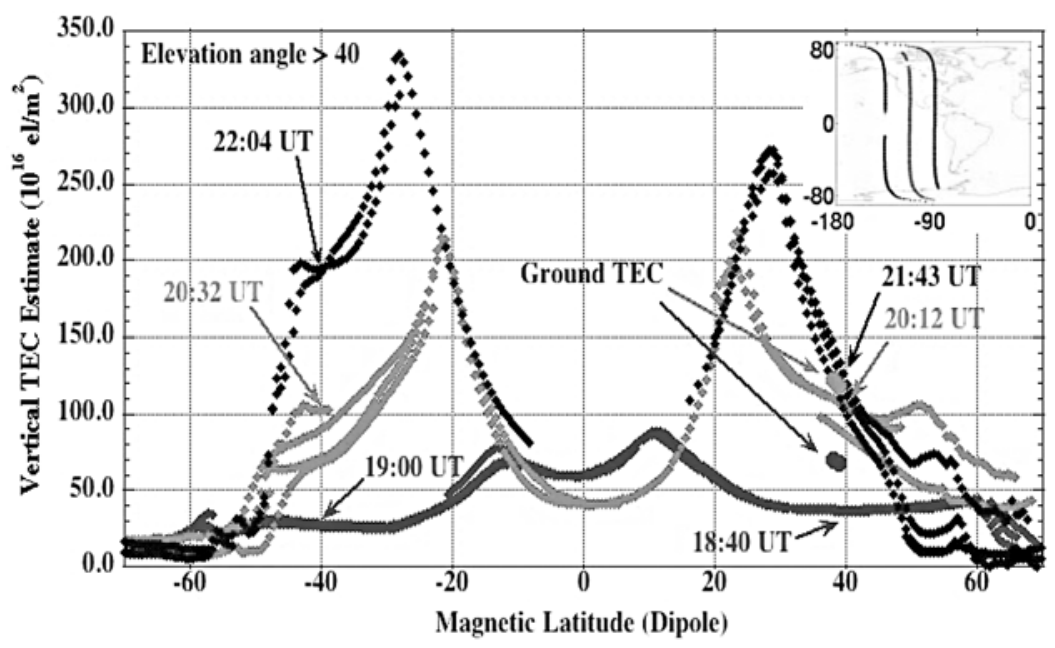

Figure 4. The TEC above the CHAMP satellite for 3 dayside passes during 30 October 2003. CHAMP covers latitudes at $\sim 13 \mathrm{LT}$ not covered by ground GPS receivers. One pass occurs prior to the IEF event and the other two after the IEF has impinged upon the Earth's magnetosphere. TEC values as high as $\sim 330$ TEC are noted. This figure is Figure 3 in Mannucci et al. [2005b].

factor of $\sim 8$ times higher than the peak diurnal electric field.

[28] It is noted that CHAMP detected even higher TEC values, but the electric field was terminated at $14 \mathrm{LT}$ in the simulations, so further comparisons between model and measurements are not meaningful.

\subsection{Oxygen Ion Uplift}

[29] Associated with the dayside ionospheric PPEF is an uplift of all plasma, not just the electrons alone. Ionospheric oxygen ion uplift is examined in Figure 6. The same electric field conditions used to simulate electron content increases shown previously in Figure 5 are assumed here. A $4 \mathrm{mVm}^{-1}$ electric field was applied from 12 LT until 14 LT. The figure has four panels. On the upper left is the SAMI2* results at $\sim 14$ LT with only the diurnal electric field imposed. The upper right-hand panel shows the model results at $\sim 14$ LT after a $4 \mathrm{mVm}^{-1}$ PPEF had been applied for $2 \mathrm{~h}$. It can be noted that for this case, the EIAs are uplifted and convected to higher absolute latitudes. The EIA peak intensities are also higher than the case without the PPEF. Enhanced ionneutral drag has been speculated to lead to enhanced lowaltitude satellite drag at dayside middle latitudes [Tsurutani et al., 2007]. These are some of other features associated with the DIS.

[30] The lower left-hand panel shows the SAMI2* model results with the PPEF present, but with solar photoionization turned off. If one compares this panel with that of the upper right-hand panel, it can be noted that the EIA peak intensities are less, and that they are located at slightly higher altitudes. There is also a strong decrease in ionization at altitudes less than $450 \mathrm{~km}$. This is particularly noticeable near the equatorial region where photoionization is strongest.

[31] The bottom right-hand panel is a continuation of the upper right-hand panel simulation after the PPEF has been turned off at 14 LT. The panel shows the oxygen ion densities after the PPEF has been turned off for $3 \mathrm{~h}$. Gravitational forces have brought the plasma down to lower altitudes. Since the plasma is confined to follow the Earth's magnetic field lines, the plasma also moves to even higher absolute latitudes. This is another feature of the DIS.

[32] The dayside ionospheric superfountain is caused by the presence of PPEFs. The PPEFs uplift the EIAs to higher altitudes and higher absolute latitudes. The uplift also leads to higher TEC magnitudes. When the electric fields cease, gravity causes the plasma to flow down the magnetic field lines to even higher absolute latitudes. Because of the convergence of magnetic fields at lower altitudes, TEC associated with the EIAs increase further.

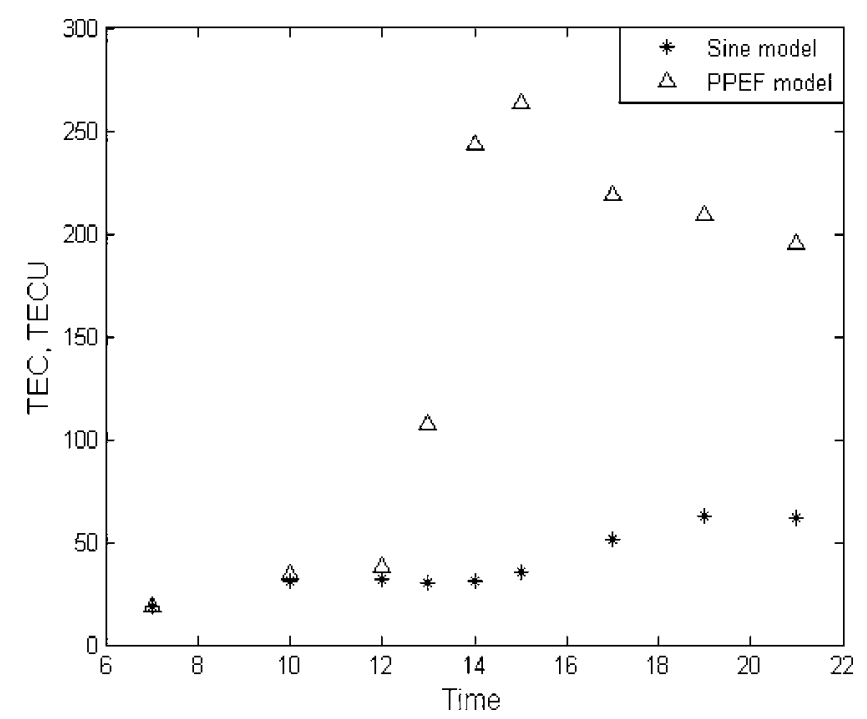

Figure 5. SAMI $*$ model simulation of the 30 October 2003 IEF event. The model calculation assumes a $4 \mathrm{mVm}^{-1}$ electric field superposed on top of a $0.53 \mathrm{mVm}^{-1}$ diurnal electric field. SAMI2* obtains a TEC value at altitudes above $430 \mathrm{~km}$ that is in excellent agreement with the CHAMP observations (Figure 4). 

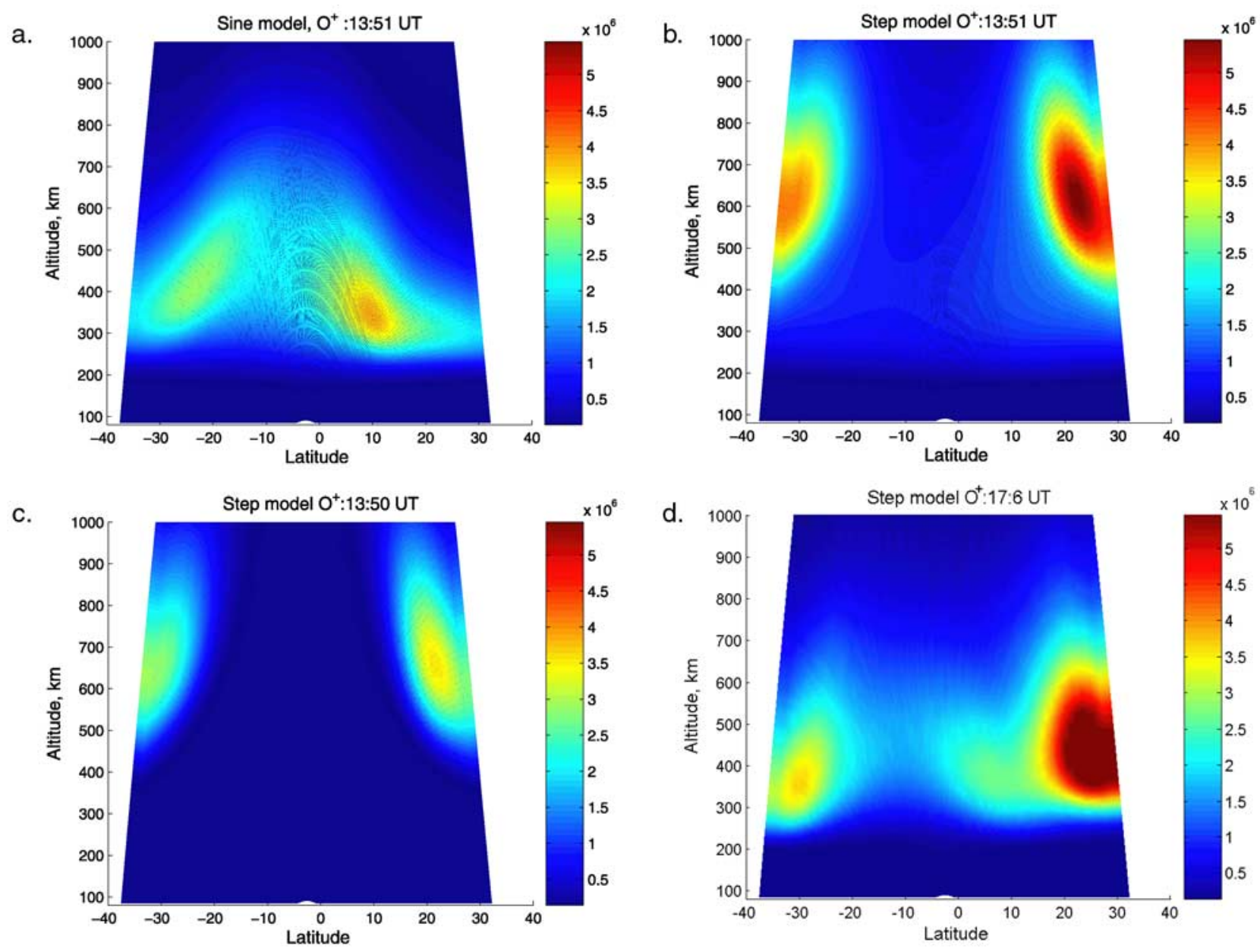

Figure 6. SAMI2* model of the 30 October 2003 oxygen ion uplift. The calculated PPEF has been used in the SAMI2* model to predict ionospheric oxygen ion uplift.

\subsection{Nighttime Effects: Negative Phase Ionospheric Storms}

[33] Southward IMF Bz fields cause a dawn-to-dusk interplanetary electric field, as mentioned previously. If these fields penetrate to the nightside equatorial/near-equatorial ionosphere, this field will be in a westward direction. The electric field will $\mathrm{E} \times \mathrm{B}$ convect the ionospheric plasma downward to lower altitudes. Chemical recombination which occurs at these lower altitudes will cause a reduction of TEC. This TEC decrease is a negative-phase ionospheric storm.

[34] The downward nighttime convection by PPEFs have been noted by S. Basu et al. [2001], Su. Basu et al. [2001], and Tsurutani et al. [2004]. It should be noted that because the ionospheric TEC decreases, rather than increases, the negative phase ionospheric storms have received far less attention recently than positive phase ionospheric storms. However, both ionospheric modifications are important from a global context.

\subsection{What Are the PPEF Ionospheric Effects at Local Times Other Than Approximately Noon and Approximately Midnight?}

[35] The PPEF effects associated with southward IMFs are strongest at the equatorial regions. The Earth's magnetic fields are horizontal there (parallel to the Earth's surface), the PPEFs are directed eastward, and thus the $\mathrm{E} \times \mathrm{B}$ convection magnitudes are the largest. The convection direction is upward near noon and downward near midnight.

[36] The PPEF effects at other local times are less well understood. We suggest two approaches to determine this. First, observations of the ionospheric electric field during large IEF intervals for all local times are needed to construct a global empirical model. Satellite and groundbased magnetometers, ionosonde and equatorial radar could be used. These observations could be compared with PPEF penetration scenarios such as those presented by Araki [1994] and DP2 current system models. The DP2 system is a twin vortex ionospheric current due to a pair of fieldaligned currents of polar origin. The afternoon vortex is larger than the morningside vortex, effectively skewing of the current system toward post-noon. This asymmetry is caused by the day-night nonuniformity of the Hall conductivity. Thus under ordinary circumstances, the equatorial component fields associated with the DP2 system are generally largest at $\sim 14$ LT. However, what is not known is if this skewing is still present or even more exaggerated during extremely intense IEFs? The empirical results suggested above should be able to provide a reasonable answer to this question. 


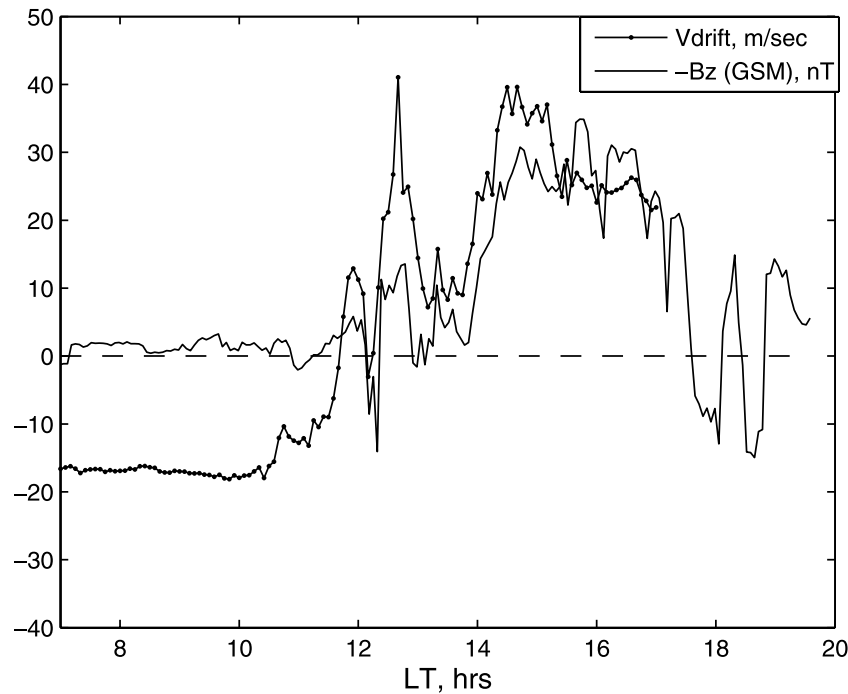

Figure 7. The ACE interplanetary magnetic field $\mathrm{Bz}$ component and ionospheric velocities over Jicamarca. The IMF - Bz and upward ionospheric velocities are correlated. This would be expected if both the eastward and westward components of the IEF penetrate to the ionosphere.

[37] While the magnetic fields are horizontal at the dawn and dusk equator, dawn-to-dusk electric fields are expected to be on the average vertically oriented at both locations (with possible exception of short-term transients). Thus the $\mathrm{E} \times \mathrm{B}$ convection direction will be eastward and westward, respectively, in contrast to either upward (noon) or downward (midnight). If these dawn and dusk electric fields are present, this should lead to dayside plasma compression. At this time, it is not known whether such convection takes place, and if so, whether it is measurable or not. If westward convection takes place at local dusk, this will be in the opposite sense to convection associated with the postdusk prereversal enhancement. Thus the presence of dawn-todusk PPEFs should suppress this latter effect.

[38] There have been previous studies of the PPEF effects in the post-dusk sector. Batista et al. [1991], Greenspan et al. [1991], and Abdu [1997] have noted that PPEFs of eastward sense act in phase with the evening prereversal enhancement of the eastward electric field resulting in enhanced ionospheric F layer uplift. Thus it appears that at times the skewing effect mentioned above leads to large eastward fields in the post-dusk hours and the effect of these fields outweigh the westward convection associated with the vertical component of these fields. In parallel with this present work, Abdu et al. [2008] have also studied the 30-31 October 2003 superstorm event. Based on VHF radar data observations over post-dusk Brazil, electric fields of order $\sim 30 \mathrm{mV} / \mathrm{m}$ were noted. This would imply not only a local time skewing effect, but a concentration of the eastward PPEF in this local time sector. It is obvious that PPEFs during this local time sector are not well understood at this time.

[39] Certainly the horizontal plasma convection associated with electric fields over the polar caps is well documented. Plasma and field lines are convected toward the antisolar direction, implying a dawn-to-dusk electric field both over the northern and over the southern polar caps.

[40] PPEF effects at other magnetic latitudes and other local times are not well understood. Systematic investigations of these important topics are still lacking and important ionospheric effects yet to be discovered may be present. We encourage interested scientists to participate in these new areas of study.

\subsection{Interpenetration of IMF By Components}

[41] There has been considerable discussion of IMF penetration into the magnetosphere for other orientations of the IMF besides southward directions. Strong IMF By components have been of particular interest. For the preferred lobe areas [see Cowley, 1981], Tsurutani et al. [1984, 1986] find that $\sim 13 \%$ of the IMF By component penetrates into the magnetotail. This number is fairly similar to the number for IEF penetration discussed previously, hence the physical process may be the similar.

[42] For positive IMF (GSM) By fields, the IEF will be in a northward direction. Since this direction is parallel to the equatorial ionospheric magnetic field, PPEF convection will be a minimum. There should be little or no associated convection in the ionosphere. Echer et al. [2008] have noted that no major (Dst $<-100 \mathrm{nT}$ ) magnetic storms during the last solar cycle was due to IMF By fields.

\subsection{Interpenetration of IMF $+\mathrm{Bz}$ (Northward) Components}

[43] Northward-directed IMFs are believed to undergo magnetic reconnection with magnetopause cusp fields [Gonzalez and Mozer, 1974; Crooker, 1979] with little or no energy flow from the solar wind to the magnetosphere or ionosphere. The magnetosphere is typically found to be at its lowest state (geomagnetic quiet) during such intervals. The amount of solar wind energy input into the magnetosphere/ ionosphere has been estimated to be 0.1 to $0.4 \%$ of the solar wind ram energy [Tsurutani and Gonzalez, 1995]. Borovsky and Steinberg [2006] have recently confirmed this finding.

[44] To test the idea of penetration of dusk-to-dawn electric fields, we examine an interval shown in Figure 7, where the IMF Bz (north-south component) fluctuates (see Verkhoglyadova et al. [2008] for details). The event is some $\sim 7 \mathrm{~h}$ of the 30 October $2003 \mathrm{IEF} / \mathrm{PPEF}$ event (from 10 to 17 Jicamarca local times). The figure shows the interplanetary Bz magnetic field superposed with the Jicamarca (near equatorial) ionospheric vertical velocities. The abscissa in the figure is the local time of the Jicamarca station. The Jicamarca data have been taken from Anderson et al. [2006]. Further details of this event can be found in Verkhoglyadova et al. [2008].

[45] What is particularly striking is the degree of correlation between the IMF $-\mathrm{Bz}$ and ionospheric drift speeds. This is remarkable given that the measurements were made over such widely separated regions of geospace. When the IMF -Bz component is positive (southward fields), the motional electric field will be in the dawn-todusk direction. An eastward PPEF implies upward dayside ionospheric $\mathrm{E} \times \mathrm{B}$ convection. This is observed at Jicamarca. On the other hand, when the IMF -Bz component is negative (northward fields), say during the sharp spike 
just after $12 \mathrm{LT}$, the plasma drift is expected to be in a downward direction. This again is what is observed. The ionosphere above Jicamarca responds rapidly to the changing IMF-Bz direction.

\section{Summary and Conclusions}

[46] Various aspects of different directions of the IMF and corresponding PPEFs have been discussed. During intense southward IMFs, magnetic storms, dayside positive phase ionospheric storms and nightside negative phase ionospheric storms are associated with the penetration of dawn-to-dusk electric fields. Convection of plasma toward local dayside should occur at dawn and dusk, but there are no confirming observations at this time.

[47] One aspect of northward IMFs was observed during the 30 October 2003 storm. For a brief interval when the IMF turned sharply northward, the dayside ionosphere over Jicamarca was convected downward, as one would expect from a dusk-to-dawn directed PPEF. At this time one does not have knowledge about longer duration northward IMFs. Will these events lead to long duration dusk-to-dawn PPEFs and negative dayside ionospheric storms? Will the nightside ionosphere indeed be uplifted?

[48] Although penetration of IMF By fields has been observed in the Earth's geomagnetic tail, the PPEF associated with this should be in a northward direction with very little effect for equatorial ionospheric convection. The presence of this PPEF in the plasma sheet does not lead to inward convection and the formation of the ring current, but rather to a twisting of the tail field and plasma. The latter has been noted by Cowley [1981] and later observationally by Sibeck et al. [1985, 1986].

[49] Detailed aspects of positive phase dayside ionospheric storms due to PPEFs have been shown in this paper. Since the EIAs are not located exactly at the equator, the PPEFs lead to transport of near-equatorial plasma to higher altitudes and latitudes. This overall feature has been called the DIS. DIS has features that indicate that it may lead to local dynamo action. Modeling will be necessary to indicate how strong a dynamo it is, and what feedback effects it may have on the ionosphere, atmosphere and the EEJ.

[50] The Fejer-Sherliess empirical model [Scherliess and Fejer, 1999] was developed for quiet time or substorm electric fields. It should be noted that $\mathrm{AE}$ or Kp indices are inadequate for extrapolation to magnetic storm magnitude electric fields. Dst or SYM-H indices should be used. The Rice Convection Model is a magnetospheric model and was not intended to be used for equatorial or near-equatorial ionospheric dynamical studies. The effects of PPEFs have been modeled by Maruyama et al. [2005] and Huba et al. [2005]. However, without an accurate estimate of the magnitude of the PPEFs to put into the above codes, DIS effects may be severely underestimated. We suggest that the Rostogi and Klobuchar [1990]/Anderson et al. [2002]/ McCreadie and Iyemori [2006] empirical technique, plus calculations presented here, be used to develop an empirical storm-time ionospheric PPEF model. A global ionospheric electric field model during superstorm intervals is greatly needed at this time.
[51] Acknowledgments. Portions of this research were performed at the Jet Propulsion Laboratory, California Institute of Technology, under contract with NASA. G.S.L. would like to thank the Council of Scientific and Industrial Research, Government of India, for support under the Emeritus Scientist Scheme. O.P.V. acknowledges a JSPS Fellowship which supported her work while at RISH, Kyoto University.

[52] Zuyin Pu thanks Joseph Huba and another reviewer for their assistance in evaluating this paper.

\section{References}

Abdu, M. A. (1997), Major phenomena of the equatorial ionospherethermosphere system under disturbed conditions, J. Atmos. Sol. Terr. Phys., 59(13), 1505.

Abdu, M. A., I. S. Batista, G. O. Walker, J. H. A. Sobral, N. B. Trivedi, and E. R. de Paula (1995), Equatorial ionospheric electric field during magnetospheric disturbances: Local time/longitude dependences from recent EITS campaigns, J. Atmos. Terr. Phys., 57, 1065.

Abdu, M. A., et al. (2008), Abnormal evening vertical plasma drift and effects on ESF and EIA over Brazil during the October 2003 superstorm, J. Geophys. Res., doi:10.1029/2007JA012844, in press.

Anderson, D., A. Anghel, K. Yumoto, M. Ishitsuka, and E. Kudeki (2002), Estimating daytime vertical $\mathrm{E} \times \mathrm{B}$ drift velocities in the equatorial $\mathrm{F}$ region using ground-based magnetometer observations, Geophys. Res. Lett., 29(12),1596, doi:10.1029/2001GL014562.

Anderson, D. N., A. Anghel, J. Chau, and O. Veliz (2004), Daytime vertical E $\times$ B velocities inferred from ground based magnetometer observations at low latitudes, Space Weather, 2, S11001, doi:10.1029/2004SW000095.

Anderson, D., A. Anghel, E. Araujo, V. Eccles, C. Valladares, and C. Lin (2006), Theoretically modeling the low-latitude, ionospheric response to large geomagnetic storms, Radio Sci., 41, RS5S04, doi:10.1029/ 2005RS003376

Araki, T. (1994), A physical model of the geomagnetic sudden commencement, Geophys. Monogr., 81, 183.

Basu, S., Su. Basu, K. M. Groves, H.-C. Yeh, S.-Y. Su, F. J. Rich, P. J. Sultan, and M. J. Keskinen (2001), Response of the equatorial ionosphere in the South Atlantic region to the great magnetic storm of July 15, 2000, Geophys. Res. Lett., 28, 3577.

Basu, Su., et al. (2001), Ionospheric effects of major magnetic storms during the International Space Weather Period of September and October 1999: GPS observations, VHF/UHF scintillations, and in situ density structures at middle and equatorial latitudes, J. Geophys. Res., 106, 30,389 .

Batista, I. S., E. R. de Paula, M. A. Abdu, and N. B. Trevedi (1991), Ionospheric effects of the 13 March 1989 magnetic storm at low latitudes, J. Geophys. Res., 96(A8), 13,943.

Blanc, M., and A. D. Richmond (1980), The disturbance dynamo, J. Geophys. Res., 85, 1669.

Borovsky, J. E., and J. T. Steinberg (2006), The "calm before the storm", in $\mathrm{CIR} /$ magnetosphere interactions: Occurrence statistics, solar-wind statistics and magnetospheric preconditioning, J. Geophys. Res., 111, A07S10, doi:10.1029/2005JA011397.

Cowley, S. W. H. (1981), Magnetospheric asymmetries associated with the y-component of the IMF, Planet. Space Sci., 29, 79.

Crooker, N. U. (1979), Dayside merging and cusp geometry, J. Geophys. Res., 84, 951.

Dungey, J. W. (1961), Interplanetary magnetic field and the auroral zones, Phys. Rev. Lett., 6, 47.

Echer, E., W. D. Gonzalez, B. T. Tsurutani, and A. L. C. Gonzalez (2008), On the solar cycle dependence of interplanetary drivers causing intense magnetic storms (Dst $\geq-100 \mathrm{nT}$ ), J. Geophys. Res.,doi:10.1029/ 2007JA012744, in press.

Foster, J. C., A. J. Coster, P. J. Erickson, J. M. Holt, F. D. Lind, W. Rideout, M. McCready, A. van Eyken, R. A. Geenwald, and F. J. Rich (2005), Multiradar observations of the polar tongue of ionization, J. Geophys. Res., 110, A09S31, doi:10.1029/2004JA010928.

Foster, J. C., and A. J. Coster (2007), Conjugate localized enhancement of total electron content at low latitudes in the American sector, J. Atmos. Sol. Terr. Phys., 69, 1893.

Fuller-Rowell, T. J., M. V. Codrescu, E. Araujo-Pradere, and I. Kutiev (1998), Progress in developing a storm-time ionospheric correction model, Adv. Space Res., 22, 821.

Gonzalez, W. D., and F. S. Mozer (1974), A quantitative model for the potential resulting from magnetopause reconnection with an arbitrary interplanetary magnetic field, J. Geophys. Res., 79(28), 4186.

Gonzalez, W. D., and B. T. Tsurutani (1987), Criteria of interplanetary parameters causing intense magnetic storms (Dst $<-100 \mathrm{nT}$ ), Planet. Space Sci., 35, 1101.

Gonzalez, W. D., B. T. Tsurutani, A. L. C. Gonzalez, E. J. Smith, F. Tang, and S. I. Akasofu (1989), Solar wind-magnetosphere coupling during intense magnetic storms (1978-1979), J. Geophys. Res., 94, 3535. 
Gonzalez, W. D., J. A. Joselyn, Y. Kamide, H. W. Kroehl, G. Rostoker, B. T. Tsurutani, and V. M. Vasyliūnas (1994), What is a geomagnetic storm?, J. Geophys. Res., 99, 5771.

Greenspan, M. E., C. E. Rasmussen, W. J. Burke, and M. A. Abdu (1991), Equatorial density depletion observed on DMSP satellites during the march 1989 storm, J. Geophys. Res., 96(A8), 13,931.

Hirono, M. (1950), On the influence of the Hall current to the electrical conductivity of the ionosphere, I, J. Geomagn., Geoelectr., 2, 1.

Huba, J. D., G. Joyce, and J. A. Fedder (2000), Sami2 is another model of the ionosphere (SAMI2): a new low-latitude ionosphere model, J. Geophys. Res., 105(A10), 23,035.

Huba, J. D., K. F. Dymond, G. Joyce, S. A. Budzien, S. E. Thonnard, J. A. Fedder, and R. P. McCoy (2002), Comparison of $\mathrm{O}^{+}$density from ARGOS LORAAS data analysis and SAMI2 model results, Geophys. Res. Lett., 29(7),1102, doi:10.1029/2001GL013089.

Huba, J. D., G. Joyce, S. Sazykin, R. Wolf, and R. Spiro (2005), Simulation study of penetration electric field effects on the low- to mid-latitude ionosphere, Geophys. Res. Lett., 32, L23101, doi:10.1029/2005GL024162,.

Kelley, M. C., B. G. Fejer, and C. A. Gonzales (1979), An explanation for anomalous equatorial ionospheric electric field associated with a northward turning of the interplanetary magnetic field, Geophys. Res. Lett., 6(4), 301.

Kelley, M. C., J. J. Makela, J. L. Chau, and M. J. Nicolls (2003), Penetration of the solar wind electric field into the magnetosphere/ionosphere system, Geophys. Res. Lett., 30(4),1158, doi:10.1029/2002GL016321.

Kikuchi, T., and T. Araki (1979), Horizontal transmission of the polar electric field to the equator, J. Atmos. Sol. Terr. Phys., 41, 917.

Lu, G., A. D. Richmond, R. G. Roble, and B. A. Emery (2001), Coexistence of ionospheric positive and negative storm phases under northern winter conditions: A case study, J. Geophys. Res., 106, 24,493.

Mannucci, A. J., B. D. Wilson, D. N. Yuan, C. M. Ho, U. J. Lindqwister, and T. F. Runge (1998), A global mapping technique for GPS-derived ionospheric total electron content measurements, Radio Sci., 33(3), 565.

Mannucci, A. J., S. Datta-Barua, T. Walter, A. Komjathy, L. Sparks, and B. T. Tsurutani (2005a), Anomalous nighttime plasma structure in the recovery phase of a superstorm, Eos Trans. AGU, 86(52), Fall Meet. Suppl., Abstract SA21A00275.

Mannucci, A. J., B. T. Tsurutani, B. A. Iijima, A. Komjathy, A. Saito, W. D. Gonzalez, F. L. Guarnieri, J. U. Kozyra, and R. Skoug (2005b), Dayside global ionospheric response to the major interplanetary events of October 29-30, 2003 "Halloween storms," Geophys. Res. Lett., 32, L12S02, doi:10.1029/2004GL021467.

Maruyama, N., A. D. Richmond, T. J. Fuller-Rowell, M. V. Codrescu, S. Sazykin, F. R. Toffoletto, R. W. Spiro, and G. H. Millward (2005), Interaction between direct penetration and disturbance dynamo electric fields in the storm-time equatorial ionosphere, Geophys. Res. Lett., 32, L17105, doi:10.1029/2005GL023763.

McCreadie, H., and T. Iyemori (2006), Equatorial electrojet as a diagnostic tool of geomagnetic field models, Earth Planets Space, 58, 885.

Namba, S., and K.-I. Maeda (1939), Radio Wave Propagation, 86 pp., Corona, Tokyo.

Nishida, A. (1968), Coherence of geomagnetic DP2 fluctuations with interplanetary magnetic variations, J. Geophys. Res., 73, 5549.

Nopper, R. W., and R. L. Carovillano (1978), Polar-equatorial coupling during magnetically active periods, Geophys. Res. Lett., 5(8), 699.

Obayashi, T. (1967), The interaction of solar plasma with geomagnetic field, disturbed conditions, in Solar Terrestrial Physics, edited by J. W. King and W. S. Newman, 107 pp., Academic, London.

Prölss, G. W. (1993), Common origin of positive ionospheric storms at middle latitudes and the geomagnetic activity effect at low latitudes, J. Geophys. Res., 98, 5981.

Prölss, G. W. (1997), Magnetic storm associated perturbations of the upper atmosphere, in Magnetic Storms, vol. 98, edited by B. T. Tsurutani, W. D. Gonzalez, Y. Kamide, and J. K. Arballo, 227 pp., AGU, Washington, D. C.

Rostogi, R. G., and J. A. Klobuchar (1990), Ionospheric electron content within the equatorial F2 layer anomaly belt, J. Geophys. Res., 95, 19,045.

Sastri, J. H. (1988), Equatorial electric fields of the disturbance dynamo origin, Ann. Geophys., 6, 635

Sastri, J. H., K. Niranjan, and K. S. V. Subbarao (2002), Response of the equatorial ionosphere in the Indian (midnight) sector to the severe magnetic storm of July 15, 2000, Geophys. Res. Lett., 29(13),1651, doi:10.1029/2002GL015133.
Scherliess, L., and B. G. Fejer (1999), Radar and satellite global equatorial F region vertical drift model, J. Geophys. Res., 104, 6829.

Sibeck, D. G., J. A. Slavin, E. J. Smith, B. T. Tsurutani, and R. P. Lepping (1985), The distant magnetotail's response to a strong interplanetary magnetic field by twisting, flattening and field line bending, J. Geophys. Res., 90, 4011.

Sibeck, D. G., J. A. Slavin, E. J. Smith, and B. T. Tsurutani (1986), Geomagnetotail twisting, in Solar Wind-Magnetosphere Coupling, edited by Y. Kamide and J. Slavin, 731 pp., Terra-Reidel, Tokyo.

Sobral, J. H. A., M. A. Abdu, W. D. Gonzalez, and I. Batista (1997), Lowlatitude ionospheric response during intense magnetic storms at solar maximum, J. Geophys. Res., 102, 14,305.

Sobral, J. H. A., M. A. Abdu, W. D. Gonzalez, C. S. Yamashita, A. L. Clua de Gonzalez, I. Batista, and C. J. Zamlutti (2001), Responses of the low latitude ionosphere to very intense geomagnetic storms, J. Atmos. Sol. Terr. Phys., 63, 965.

Tsurutani, B. T., and W. D. Gonzalez (1995), The efficiency of "viscous interaction" between the solar wind and the magnetosphere during intense northward IMF events, Geophys. Res. Lett., 22, 663.

Tsurutani, B. T., D. E. Jones, R. P. Lepping, E. J. Smith, and D. G. Sibeck (1984), The relationship between the IMF By and the distant tail (150$238 \mathrm{Re}$ ) lobe and plasma sheet By fields, Geophys. Res. Lett., 11, 1082.

Tsurutani, B. T., B. E. Goldstein, M. E. Burton, and D. E. Jones (1986), A review of the ISEE-3 geotail magnetic field results, Planet. Space Sci., 34, 931 .

Tsurutani, B. T., et al. (2004), Global dayside ionospheric uplift and enhancement associated with interplanetary electric fields, J. Geophys. Res., 109, A08302, doi:10.1029/2003JA010342.

Tsurutani, B. T., R. L. McPherron, W. D. Gonzalez, G. Lu, J. H. A. Sobral, and N. Gopalswamy (2006), Introduction to a special section on corotating solar wind streams and recurrent geomagnetic activity, J. Geophys. Res., 111, A07S00, doi:10.1029/2006JA011745.

Tsurutani, B. T., O. P. Verkhoglyadova, A. J. Mannucci, T. Araki, A. Saito, T. Tsuda, and K. Yumoto (2007), Oxygen ion uplift and satellite drag effects during the 30 October 2003 daytime superfountain event, Ann. Geophys., 25, 569 .

Vasyliūnas, V. M. (2001), Electric field and plasma flow: What drives what?, Geophys. Res. Lett., 28, 2177.

Vasyliūnas, V. M. (2005a), Time evolution of electric fields and currents and the generalized Ohm's law, Ann. Geophys., 23, 1347.

Vasyliūnas, V. M. (2005b), Relation between magnetic fields and electric currents in plasmas, Ann. Geophys., 23, 2589.

Verkhoglyadova, O. P., B. T. Tsurutani, and A. J. Mannucci (2006), Modeling of time development of TEC variations during a superstorm event, in Advances in Geosciences, vol. 8, edited by M. Duldig et al., p. 69, World Sci., Hackensack, N. J.

Verkhoglyadova, O. P., B. T. Tsurutani, A. J. Mannucci, A. Saito, T. Araki, D. Anderson, M. Abdu, and J. H. A. Sobral (2008), Simulation of PPEF effects in dayside low-latitude ionosphere for the October 30, 2003 superstorm, in Mid-Latitude Ionosphere Dynamics and Disturbances, edited by P. Kintner et al., AGU, Washington, D. C., in press.

M. A. Abdu, W. D. Gonzalez, and J. H. A. Sobral, INPE, Sao Jose dos Campos, 12201-970 Sao Paulo, Brazil.

T. Araki and A. Saito, KUGI, Kyoto University, 606-8502 Kyoto, Japan.

G. S. Lakhina, Indian Institute of Geomagnetism, 400005 Mumbai, India.

A. J. Mannucci and B. T. Tsurutani, Jet Propulsion Laboratory, California Institute of Technology, Pasadena, CA 91109, USA. (bruce.t. tsurutani@jpl.nasa.gov)

H. McCreadie, Department of Earth and Environmental Sciences, Ludwig-Maximilians University, D-80333 Munich, Germany.

T. Tsuda RISH, Kyoto University, Uji, 611-0011 Kyoto, Japan.

V. M. Vasyliūnas, Max Planck Institute for Solar System Research, D-37191, Katlenburg-Lindau, Germany.

O. P. Verkhoglyadova, IGPP, University of California, Riverside, CA 92521, USA.

K. Yumoto, SERC, Kyushu University, 812-8581 Fukuoka, Japan. 